\title{
O trabalho de campo como estratégia de educação ambiental nas escolas: uma proposta para o ensino médio
}

\author{
Gustavo Pereira Pessoa ${ }^{1}$ \\ Rosalina Batista Braga ${ }^{2}$
}

Resumo: Esta pesquisa objetivou avaliar o trabalho de campo como estratégia para a promoção da educação ambiental com alunos do ensino médio. Trabalhos sobre essa temática se justificam porque, apesar do aumento de iniciativas de educação ambiental nas escolas, essas atividades ainda carecem de mais eficácia e sistematização. Compuseram a metodologia da pesquisa em questão: levantamento inicial dos significados ambientais já construídos pelos alunos, dois processos de trabalhos de campo em dois diferentes ambientes, instrumentalização teórica entre os dois momentos de trabalho de campo e entrevistas de aprofundamento com alguns alunos da turma investigada. Consideráveis mudanças foram identificadas na percepção dos estudantes após a realização dos últimos trabalhos de campo. As conclusões do estudo, pautadas pelos dados obtidos durante os trabalhos de campo e pelas entrevistas, indicaram o grande potencial do trabalho de campo para a educação ambiental quando realizado com consequente planejamento.

Palavras-chave: Educação ambiental. Percepção ambiental. Trabalho de campo. Ensino médio.

\section{Field work as an environmental education strategy in schools: a proposal for high school}

Abstract: This research aimed to evaluate field work as a strategy for the promotion of environmental education among high school students. Works on this theme are justified because, despite the increase in environmental education initiatives in schools, these activities still lack efficiency and systematization. The research methodology consisted of an initial survey of environmental meanings already built by the students, two sets of field work activities performed in two different environments, teaching activities carried out between the two stages of field work, and interviews with some students of the investigated class. Considerable

\footnotetext{
${ }^{1}$ Mestre em Gestão Social, Educação e Desenvolvimento Local. Instituto Federal de Minas Gerais(IFMG), Congonhas, Brasil, gustavo.pessoa@ifmg.edu.br

${ }^{2}$ Docente do Mestrado em Gestão Social, Educação e Desenvolvimento Local do Centro Universitário UMA , Belo Horizonte , Brasil, rosalinabraga@gmail.com
} 
changes were identified in the perception of students after the last set of field work activities. The conclusions of the study, based on data collected during the field work activities and the interviews, indicate the great potential of field work for environmental education when it is performed with sensible planning.

Keywords: Environmental education. Environmental perception. Field work. High school.

\section{El trabajo de campo como estrategia de educación ambiental en las escuelas: una propuesta para el bachillerato}

Resumen: Esta investigación tuvo como objetivo evaluar el trabajo de campo como estrategia para la promoción de la educación ambiental con alumnos del bachillerato. Trabajos sobre esta temática se justifican porque, a pesar del aumento de iniciativas de educación ambiental en las escuelas, estas actividades aún carecen de más eficacia y sistematización. Compusieron la metodología de la investigación en cuestión: levantamiento inicial de los significados ambientales ya construídos por los alumnos, dos procesos de trabajos de campo en dos diferentes ambientes, instrumentalización teórica entre los dos momentos de trabajo de campo y entrevistas de perfeccionamiento con algunos alumnos del grupo investigado. Se identificaron cambios considerables en la percepción de los estudiantes después de la realización de los últimos trabajos de campo. Las conclusiones del estudio, pautadas por los datos obtenidos durante los trabajos de campo y por las entrevistas, indicaron el gran potencial del trabajo de campo para la educación ambiental cuando se realiza con un planeamiento consecuente.

Palabras clave: Educación ambiental. Percepción ambiental. Trabajo de campo. Bachillerato.

\section{Introdução}

Este artigo apresenta os resultados de uma investigação realizada no curso de Mestrado em Gestão Social, Educação e Desenvolvimento Local do Centro Universitário UNA. A pesquisa teve como objeto a identificação de elementos e de processos mais relevantes para se desenvolver a sensibilização ambiental de estudantes de ensino médio durante atividades de trabalhos de campo. Para desvendar a questão de pesquisa, traçou-se um desenho metodológico para captar as percepções ambientais dos estudantes em três momentos: antes do início de qualquer atividade relacionada ao estudo, durante a realização de 
trabalhos de campo - sem qualquer atividade de instrumentalização teórica - e após a apresentação de conteúdo teórico e a repetição dos trabalhos de campo, realizados nas mesmas áreas daqueles efetuados no primeiro momento. A partir das percepções identificadas, buscou-se sistematizar os aspectos mais significativos de uma atividade de trabalho de campo direcionada para a prática da educação ambiental (EA).

A educação ambiental como prática escolar cresceu consideravelmente nos últimos anos. Esse crescimento, entre outros fatos, está ligado ao crescimento dos problemas ambientais. Apesar do aumento da EA nas escolas, suas atividades devem ser problematizadas quanto aos seus significados, alcances e desdobramentos. Dados de pesquisa realizada por Loureiro et al. (2006) mostram que, de forma geral, as práticas de educação ambiental ficaram mais frequentes nas escolas, porém, seus limites são significativos. Desses limites podem-se destacar a descontinuidade das práticas e as consequências de serem assentadas na organização disciplinar das escolas. Esse tipo de situação é muito comum, pois o processo de escolarização da educação ambiental se dá em escolas concretas, com seus limites e impasses. Alguns desses impasses referem-se à estrutura disciplinar das escolas. A referida pesquisa identificou que dominam nas escolas as iniciativas de EA apresentadas, centralmente, pelos docentes de Biologia, em primeiro lugar, e de Geografia, em segundo.

Outra questão identificada nas experiências docentes analisadas foi que as práticas de EA nas escolas não têm resultado em mudanças de significados que sustentem mobilização e mudanças de atitudes dos alunos diante das questões ambientais.

Tendo em conta os desafios da EA escolar, este estudo procurou construir, com os alunos, uma abordagem que permitisse politização e ressignificação da percepção e da apropriação do espaço no que se refere à questão ambiental. O trabalho de campo foi visto como uma estratégia, uma ferramenta para promover a EA nas escolas e superar barreiras referentes à reconstrução de significados ambientais com os alunos. Sendo uma atividade na qual o estudante teria contato direto com o meio estudado, existia a possibilidade de que, após a sistematização dos dados levantados, se verificassem mudanças de significados superiores àquelas que têm acontecido a partir das práticas discursivas em sala de aula.

Trabalhou-se com a hipótese de que a associação dos dados sensoriais com adequado aporte teórico poderia promover mudança de compreensão sobre a construção e apropriação do espaço pelos estudantes e esse fato poderia alterar os significados já construídos pelos alunos sobre as questões ambientais.

\section{Conceitos norteadores da investigação}

Torna-se necessário, então, apresentar, de forma sintética, os conceitos que nortearam a pesquisa e que fundamentaram a análise dos dados obtidos. 
O conceito norteador foi o de meio ambiente, que se caracteriza por uma grande polissemia. Por isso, é fundamental situar como ele foi concebido na pesquisa, pois a prática de EA é diferente a depender de como esse conceito é formulado. Neste trabalho optou-se por adotar o conceito de meio ambiente proposto por Reigota (2007). Segundo o autor, meio ambiente é definido como

[...] lugar determinado ou percebido, onde os elementos naturais e sociais estão em relações dinâmicas e em interação. Essas relações implicam processos de criação cultural e tecnológica e processos históricos e sociais de transformação do meio natural e construído. (REIGOTA, 2007, p. 14).

No texto citado, o autor indica claramente as dimensões sócio-histórica e humana como parte integrante e transformadora do meio ambiente. Além disso, afirma a complexidade constitutiva do meio ambiente e frisa que este também é percebido, já que cada indivíduo o interpreta de acordo com seus conhecimentos, vivências, cultura e experiências, sendo essa questão de grande relevância nesta pesquisa.

Reforçando essas ideias, Soares (2008, p. 34) afirma:

Meio ambiente torna-se, assim, um conceito abrangente e produto da ação e da organização humana. Sob este aspecto, diferente do que muita gente apregoa, meio ambiente não se reduz apenas a recursos naturais. Meio ambiente diz respeito ao receptáculo de toda atividade humana $[\ldots]$.

Considerou-se que o significado de meio ambiente é revelado pelas percepções que se têm do mesmo. Logo, quando se trabalha com essa percepção, têm-se chances de contribuir para a reconstrução dos significados e a ressignificação das concepções relativas ao meio ambiente. Essa escolha foi fundamental, visto que se partiu dos significados já concebidos pelos estudantes sobre os espaços a serem estudados. As escolhas de quais espaços seriam objeto dos trabalhos de campo foram retiradas das percepções iniciais dos estudantes, identificadas por um diagnóstico inicial.

Outro conceito que serviu de guia para as atividades da pesquisa foi o de interdisciplinaridade. Procurou-se posicionar-se em relação a esse conceito devido ao fato de ser ele também polissêmico e de a EA ser, por necessidade, uma prática interdisciplinar. O conceito foi formulado com o apoio das concepções de Nicolescu (1999, p. 2), que vê a interdisciplinaridade como 
[...] uma ambição diferente daquela da pluridisciplinaridade.

Ela diz respeito à transferência de métodos de uma disciplina para outra. Podemos distinguir três graus de interdisciplinaridade:

a) um grau de aplicação. Por exemplo, os métodos da Física Nuclear transferidos para a Medicina levam ao aparecimento de novos tratamentos para o câncer; b) um grau epistemológico. Por exemplo, a transferência de métodos da lógica formal para o campo do direito produz análises interessantes na epistemologia do direito; c) um grau de geração de novas disciplinas. Por exemplo, a transferência dos métodos da Matemática para o campo da Física gerou a Física Matemática. (Grifos do autor).

Apesar de ter uma raiz disciplinar, a interdisciplinaridade avança muito em relação à pluridisciplinaridade, pois ocorre parcialmente o "rompimento" das barreiras estabelecidas pelo pensamento disciplinar, o que permite a construção de novos conhecimentos baseados na interação metódica das disciplinas. A referida construção, que valoriza a integração das diferentes disciplinas, permite percepção mais ampla da complexidade que forma o mundo (NICOLESCU, 1999).

Outro procedimento fundamental foi definir o entendimento de trabalho de campo, visto ter sido a estratégia pedagógica utilizada na pesquisa. Essa determinação se fez necessária devido às muitas formas de concebê-lo e desenvolvê-lo, o que poderia levar a confusões numa atividade de produção do conhecimento escolar e, simultaneamente, científica. Optou-se por entender o trabalho de campo como forma de produção participativa de conhecimento, ou seja, nele deve existir um planejamento prévio e as atividades programadas devem incluir, em seu planejamento e execução, os alunos para oportunizar a produção e reprodução de conhecimentos. $\mathrm{O}$ trabalho de campo não é visto como um fim em si mesmo, mas um meio pelo qual o aluno pode compreender a realidade e a totalidade do mundo, a partir da leitura e percepção do espaço vivido/concebido, levando em conta a complexidade de relações sociais que dele fazem parte (LIMA; ASSIS, 2005).

Foram projetados trabalhos de campo que levassem em conta os significados preexistentes dos estudantes, por se considerar que estes já possuíam percepções sobre os espaços a serem estudados. Outra consequência importante desse entendimento foi a participação dos estudantes na escolha dos espaços a serem estudados, pois esses espaços pertenciam às suas realidades e agasalhavam os significados até então construídos por eles. Foi a partir da relevância desses significados construídos que os espaços para os trabalhos de campo foram escolhidos.

\section{Construção do desenho metodológico da pesquisa}


Para a realização da coleta de dados empíricos foi construído um desenho metodológico estruturado em cinco momentos distintos, que são apresentados a seguir.

No primeiro momento, ocorreu a aplicação de um questionário exploratório (diagnóstico) que teve várias funções, entre elas a de servir de orientação para a construção dos roteiros de trabalho de campo e, principalmente, captar aspectos da percepção ambiental dos estudantes sobre as localidades que eles frequentavam no cotidiano. Por intermédio desse questionário foram selecionados os locais de ocorrência dos trabalhos de campo, levando-se em conta as percepções positivas e negativas a respeito de espaços de vivência dos estudantes. A partir das justificativas para qualificar um local como bom ou ruim, inferiram-se as variáveis consideradas para a construção das percepções dos alunos a respeito dos ambientes.

No segundo momento, ocorreram as primeiras atividades de campo. Uma delas foi realizada em um local que a maioria dos alunos associava a vivências positivas e outra, em um local que a maioria dos alunos associava a vivências negativas. Os estudantes indicaram a escola como local de vivências positivas e algumas ruas do bairro como locais de vivências negativas. Por isso, um trabalho de campo ocorreu na escola e outro, em algumas das ruas relacionadas pelos alunos. Não houve a introdução de aportes teóricos previamente a essas primeiras atividades de campo. Os estudantes exploraram nos espaços estudados a percepção sensorial, inicialmente desdobrada em cada um dos sentidos. Posteriormente, em cada ponto de parada para observação, foi proposta a articulação das percepções de todos os sentidos. Essas percepções, as oriundas de cada sentido e as articuladas, foram registradas em um caderno de campo que foi entregue a cada aluno para a anotação dos dados. No terceiro momento, introduziu-se a abordagem teórica, que ocorreu na forma de duas aulas sobre temas relativos aos espaços estudados. Nessa atividade as temáticas foram apresentadas de forma que os estudantes, numa futura atividade de campo, dispusessem de informações teoricamente sistematizadas que pudessem ser associadas aos fenômenos observados, ampliando as suas possibilidades de percepção. O quarto momento consistiu na repetição das atividades de campo, nos mesmos locais do segundo momento. Cada atividade foi procedida com a mesma sistemática do segundo momento, porém, agora os estudantes dispunham de aportes teóricos trabalhados no terceiro momento.

Durante o quinto e último momento, ocorreu o aprofundamento de alguns dados por meio da realização de entrevistas com alunos que representavam grupos de percepções similares. Foram definidos representantes de três tipos de perfis de aluno: um grupo constituído por alunos cujas percepções iniciais não apresentaram alterações significativas; um grupo que só revelou alterações no ambiente das ruas; e um grupo que revelou alterações nas percepções dos dois 
ambientes. De cada grupo foi escolhido para as entrevistas um representante de cada sexo, com exceção do grupo que não revelou alterações em suas percepções, visto que esse grupo foi constituído apenas por mulheres. As entrevistas buscaram confirmar os dados das etapas anteriores e aprofundar e esclarecer aspectos das mudanças ou permanências das percepções dos alunos.

\section{Apresentação e análise dos dados}

No primeiro momento, a aplicação do questionário exploratório (diagnóstico) teve a função de fornecer dados sobre as percepções e significados ambientais construídos pelos alunos da turma investigada, pertencente ao primeiro ano do ensino médio de uma escola estadual da periferia de Belo Horizonte. As principais informações obtidas por meio desse instrumento versavam sobre a percepção desses estudantes a respeito dos espaços nos quais conviviam. A partir desse instrumento, foi possível apurar quais locais os estudantes percebiam como positivos e os motivos para esse tipo de percepção e os locais que percebiam como negativos e por quê.

Como local majoritário de percepção positiva foi citada a escola. As justificativas predominantes indicaram a escola como lugar de convivência, espaço que favorecia as interações, sobretudo de colegas e amigos, lugar de encontro entre pessoas. Os locais aos quais foram atribuídas percepções negativas formam um conjunto de ruas do bairro, e as justificativas para essa percepção também estão associadas à socialização, com predominância para a ocorrência de violências entre as pessoas.

Esses e outros dados obtidos por meio do questionário, como acesso a fontes de informação, percepção do belo e agradável e do feio e desagradável, participação em movimentos sociais, percepção dos movimentos de bairro e outros, foram utilizados na construção dos roteiros de trabalho de campo. Sendo assim, os roteiros para os trabalhos de campo foram concebidos levando-se em conta os significados ambientais construídos nas vivências dos estudantes.

O segundo momento de coleta de dados, que incluiu os primeiros trabalhos de campo, ocorreu na escola e em algumas ruas do bairro identificadas como locais desagradáveis. Essa fase deu-se antes da introdução de qualquer reflexão teórica. Na maioria dos casos os estudantes que participaram da atividade listaram os elementos sem estabelecer qualquer relação entre eles. Ao final, mesmo quando solicitados a apresentar as interações dos elementos observados e percebidos, poucos alunos construíram interações. Esse fato pode ser evidenciado no seguinte trecho, em que o aluno descreve a sala de aula utilizando o tato: "A parede é lisa, plana e gelada. As carteiras são geladas e planas. Tinha uma carteira molhada. O vidro é plano e gelado, o teto é cheio de frisos, o quadro é liso e áspero, a cerâmica é lisa e gelada" (Aluno A). 
Nessa fala percebe-se a ausência de relações entre os elementos do espaço. O resultado expressa centralmente uma percepção sensória não integrada, que constitui parte da percepção dos indivíduos, segundo as formulações de Chaú́ (2000). Para a autora, a percepção é formada por um conjunto de sensações associadas. Essa associação se dá pelos elementos sensórios entre si e destes com as noções, significados, concepções e valores preexistentes nas construções dos sujeitos, sendo fundamental na interpretação dos ambientes. Nessa etapa da pesquisa não ocorreu, de forma significativa, a expressão da associação das dimensões sensórias e a sua articulação, o que implicaria uma visão integrada do ambiente. Seguindo o exposto, pode-se ainda afirmar que nessa etapa do estudo a percepção dos estudantes não se aproxima do conceito de meio ambiente proposto por Reigota (2007), também presente na Lei n ${ }^{\circ}$ 9.795, de 1999, que instituiu a Política Nacional de Educação Ambiental (BRASIL, 1999). No texto da lei o meio ambiente é conceituado considerando-se as inter-relações dos seus elementos constitutivos. Contudo, nas anotações dos alunos, não foi possível identificar uma percepção que articulasse os elementos constitutivos do ambiente; ao contrário, os aspectos físicos e biológicos do espaço foram apresentados de forma estanque, sem inter-relações.

No trabalho de campo realizado nas ruas do bairro, a exemplo da atividade realizada na escola, não houve articulação entre os elementos percebidos no meio. Nessa etapa os estudantes preocuparam-se em criar listas dos elementos percebidos nos locais, mesmo quando foram estimulados para articular esses elementos. Os trechos a seguir, que descrevem um centro comunitário de esportes localizado em uma importante avenida do bairro, justificam a nossa afirmação:

Tem prédios, ponto de ônibus, quadra de futebol, casas com tijolos à mostra, pessoas fazendo caminhada, movimento de automóveis, muitas arvores no local, várias placas de sinalização. (Aluno G).

Prédios, árvores, casas, quadra poliesportiva, veículos, pessoas, postes de luz, antena parabólica [...] barulho de automóveis, pássaros cantando, pessoas conversando, rádio tocando. (Aluno B).

Nessas duas transcrições ocorreu simplesmente o registro de elementos justapostos no ambiente, sem se atentar para as relações entre eles. A razão para esse tipo de registro, provavelmente, está relacionada à ausência de visão integrada do ambiente e de abordagem teórica que explicite a complexidade do meio ambiente.

Nesse momento da coleta de dados a falta de elementos teóricos na percepção do ambiente ficou nítida, pois os estudantes perceberam o ambiente sem qualquer aporte, não conseguiram fazer mais do que captar os elementos e listá-los. Como a percepção é formada por um conjunto de sensações associadas 
a valores, concepções e referências anteriores, nessa etapa os estudantes não possuíam referências articuladas sobre esses ambientes. Os relatos foram apresentados numa forma muito pouco elaborada, revelando uma percepção fragmentada, sem dinâmica e movimento entre os elementos.

Entretanto, em alguns registros, como exceções, apareceram percepções mais elaboradas, como no texto a seguir, no qual surge a indicação da presença do ser humano integrando o meio ambiente e alguma articulação entre os elementos: "Barulho dos automóveis, motocicleta, caminhões, barulho do cano quebrado, das pessoas falando, barulho da água na pista quando os carros passam, barulho das pessoas caminhando, o som que mais se destaca é dos carros" (Aluno G).

$\mathrm{O}$ texto exposto pode indicar que o estudante não percebeu esse meio por um viés naturalista, ele não vê as relações do ser humano com o ambiente, mas o ser humano como parte do ambiente. A percepção do elemento humano no ambiente indica que ele não percebeu o ambiente como externo ao homem. Nesse caso, o estudante estaria fora do grupo majoritário que vê o ser humano como externo ao meio ambiente, fato que é salientado por Reigota (2007) e Suetergaray (2002). Segundo esses autores, o homem é dominantemente percebido como externo à noção de meio ambiente, o que não ocorreu com esse estudante. Outro fato ocorrido nesse momento e que merece destaque foi a identificação da urbanização desordenada, característica da região de ocorrência dos trabalhos. Apesar de não existirem relações expostas nos registros, esse fenômeno foi percebido, como confirmam os relatos a seguir:

Muito mato, os carros bem longe na avenida, muitas casas juntas, uma dona estendendo roupa, várias cores e formas diferentes, cachorros e muito entulbo. (Aluno D).

Muitas casas construídas em barrancos, muito juntas, galinhas soltas no quintal, um rio a céu aberto, muita vegetação ao redor, pessoas com roupas simples, alguns carros velhos, entulho as margens do córrego. (Aluno G).

Apesar de não haver relações explicitando a urbanização típica do local, a percepção da mesma facilitou a construção dessas relações na fase de introdução do aporte teórico. $\mathrm{O}$ aluno, no texto anterior, estabelece uma expressão inquietante: fala de "um rio a céu aberto". Estaria ele se referindo a um esgoto a céu aberto ou considera que todos os rios devam ser canalizados, encobertos?

O terceiro momento do trabalho, como já situado, consistiu na realização de uma instrumentalização teórica em duas aulas sobre temas referentes aos locais onde foram feitos os trabalhos de campo e baseadas nos resultados dos primeiros trabalhos de campo. Referentes aos espaços das ruas do bairro, foram abordados os temas: impermeabilização do solo, urbanização brasileira, urbanização 
desordenada, consequências do processo de urbanização desordenada, condições para a criação e preservação da qualidade de vida, histórico do bairro e sua relação com a configuração do bairro, importância das ruas como espaço de socialização. No caso do trabalho de campo na escola, foram citados: condições socioespaciais da organização do espaço escolar, função social da escola, história e importância daquela escola no bairro.

No trabalho de campo realizado na escola após a instrumentalização teórica, houve considerável ganho na percepção dos estudantes, pois eles começaram a estabelecer algumas relações existentes entre os elementos do espaço. A percepção da função social da escola também apareceu com grande destaque nos registros, o que no momento anterior não havia ocorrido. Os espaços que no momento anterior eram descritos agora são percebidos com qualidades e funções. O trecho a seguir exemplifica essa mudança na percepção do local: "Os meninos dentro da sala de aula estudando, sendo ensinados para que seu futuro seja bem aprimorado" (Aluno D descrevendo uma visão a partir do pátio da escola).

Nessa transcrição, a escola é caracterizada com uma função e um objetivo. Aparece o papel de produção e reprodução da cultura, o qual caracteriza e define a instituição escolar. Brandão (1991) lembra que a educação é uma fração do modo de vida de uma comunidade, logo, a escola, por ser uma instituição de ensino, possui na função "ensinar" essa fração de modo de vida. Pode-se considerar que o Aluno D conseguiu perceber características do ambiente que não são materiais e são importantes nas interpretações desse espaço. Essa percepção da função da escola também aparece em trecho do Aluno A: "É um ambiente humanizador que faz parte da escola e leva as pessoas a serem mais respeitosas, ajudando aos outros e fazendo as pessoas a pensar [sic] no próximo com uma educação digna" (Aluno A).

Para o Aluno A, a utilização do termo humanizador remete ao papel de formação humana para o convívio social que cabe à escola. Esse estudante foi capaz de perceber a função daquele espaço, o que não ocorreu no momento anterior à introdução do aporte teórico.

A percepção do ambiente influenciada por fatores ligados à socialização também foi recorrente, o que reforça a ideia extraída do questionário inicial de que tais fatores são relevantes na construção da percepção ambiental dos alunos. A fala a seguir deixa isso explícito: "Um lugar iluminado (sala de aula), várias pessoas, várias carteiras, as pessoas estão se socializando umas com as outras, podendo, assim, ter uma convivência mais agradável" (Aluno D).

Fica fácil perceber nesse depoimento que há uma condição existente entre o fator socialização e a qualidade do ambiente: iluminação e interações socais são percebidas e articuladas. Nota-se como as interações sociais são fundamentais para a percepção do ambiente. Esse pensamento vai ao encontro das concepções de lugar defendidas por Leite (1998). A partir da percepção de que há 
socialização no ambiente, este se torna mais agradável, podendo ser considerado lugar para aquele indivíduo. Vale ressaltar que isso só é possível quando o indivíduo percebe o ambiente em suas várias dimensões, o que ocorreu, predominantemente, no segundo momento de trabalhos de campo, após a instrumentalização.

No trabalho de campo realizado nas ruas do bairro após a instrumentalização, também houve ganho na percepção do ambiente. Foi possível notar que os elementos que antes eram listados agora aparecem articulados entre si. Provavelmente, isso se explica devido à associação da abordagem teórica com a percepção sensória, recompondo as concepções dos estudantes. Nesse momento pode-se considerar que se constituiu a percepção do ambiente de acordo com o conceito proposto por Chauí (2000): um conjunto constituído pelo sensório associado às abstrações, construindo as concepções em seus movimentos.

Os alunos a seguir exemplificam o que foi exposto:

O córrego poluido, com risco de enchentes e que provoca doenças, casas mal construídas, com risco de desabamento, pessoas gente boa apesar da vida, árvores com boa distribuição apesar da urbaniz̧ação, entulhos que podem dar abrigo a animais como escorpiões e aranhas. (Aluno A).

Na maioria dos lugares as casas são muito próximas umas das outras, amontoadas e desorganizadas. Alguns dos lugares que a gente pode observar, como o centro poliesportivo, é um lugar no qual as quadras são bem conservadas, onde os moradores possuem bom lazer, pois o lugar é plano e ótimo pra praticar exercícios físicos. A avenida T.C. é um lugar bem movimentado [que] possui bastante movimento de carros e em alguns lugares mau cheiro, ratos e insetos (o que pode causar mal à saúde das pessoas que ali habitam). (Aluno $G$ ).

Nesses registros observou-se muito mais articulação dos elementos do meio, o que demonstra que nessa etapa a compreensão de meio ambiente dos estudantes foi ampliada, aproximando-se da definição defendida por Reigota (2007). Quando há a percepção das relações entre os elementos, o ambiente é percebido de modo mais amplo e dinâmico, mais próximo do que ele é de fato em sua complexidade.

Relações referentes às condições das moradias e à qualidade de vida foram bastante frequentes. Os estudantes reconheceram que vários fatores integram a qualidade de vida. As três transcrições a seguir evidenciam essa percepção:

Um monte de entulho às margens do córrego (gerando um lugar propício para ratos, insetos e outros se esconderem, afetando a saúde das pessoas), casas construidas perto do 
córrego, uma em cima da outra (muitas sofrem com enchentes) e o córrego B.S. todo cheio de lixo. (Aluno E).

Sabor azedo (devido ao cheiro de carniça do rato morto), um ambiente não saudável para a vida humana. (Aluno E).

Arvores altas e bem estruturadas; lixo espalhado por todo lado, ambiente sujo, muitos carros, para um ambiente educativo (poliesportivo) esse local é muito sujo e desorganizado [...] carros com um barulho alto que incomoda [...] muito barulhento para um local educativo. (Aluno I).

A percepção ligada aos riscos à saúde também foi uma novidade que apareceu após as aulas de instrumentalização. Obter esse tipo de resultado foi muito importante, visto que as condições de saúde são fundamentais para a boa qualidade de vida. No momento anterior, as características do meio não apareciam relacionadas às condições de saúde no mesmo, sendo esse um importante ganho na percepção.

A percepção do processo de urbanização desordenada ocorreu novamente, mas desta vez esse processo foi mais bem caracterizado e relacionado a outros fatores ambientais. Nos registros a seguir estão exemplos desse avanço de percepção:

Movimento de pessoas em nossa volta andando, automóveis passando a todo momento, casas mal organizadas (desordenadas) e sem acabamento preciso do seu lado externo. (Aluno G).

Área transformada também em espaço urbano, casas com passagens curtas, urbanização desorganizada, carros passando. Quadra de esportes onde se pode ter um pouco de lazer, prédios bem estruturados e casas em locais perigosos, pouca vegetação. (Aluno H).

A percepção da impermeabilização do solo e sua relação com a ocorrência de enchentes também foi notada, o que não ocorreu antes, mesmo porque um dos locais do trabalho fica em uma das áreas mais susceptíveis à ocorrência de enchentes no município de Belo Horizonte. O Aluno E registra essa relação de forma bem clara: "Lugar movimentado (automóveis e pessoas); as casas em volta são mal-acabadas, simples e muito próximas, poucas árvores devido às construções, as águas da chuva não têm onde penetrar, causando enchentes no ribeirão A".

A relação de consequência estabelecida pelo Aluno E comprova mais uma vez que houve ganho na percepção dos participantes da atividade, considerando que essa relação não é um elemento material e ainda assim foi percebida, o que não ocorreu no primeiro trabalho. Pode-se considerar que os fundamentos 
teóricos associados à observação proporcionaram esse ganho de percepção, pois o que se tem nesse momento é a associação da percepção sensória com os aportes teóricos apresentados nas aulas.

Apesar de ter sido trabalhada nas aulas uma concepção abrangente de meio ambiente, apareceram, em alguns relatos, percepções ligadas à concepção de meio ambiente como algo igual à natureza in natura. Nos dois próximos textos a palavra "natureza" aparece como sinônimo de "vegetação". Apesar de existirem muitas pessoas no ambiente, elas não foram notadas. Esses relatos passam, portanto, a ideia de natureza exterior ao ser humano, que é criticada por Santos (2007).

[...] grande fluxo de automóveis, com bastantes árvores, casas nobres e um poliesportivo bumilde como a presença da natureza. (Aluno $G$ ).

[...] Perto de prédios e um poliesportivo "nobre", ou seja, uma classe pobre ao lado de outra "rica" e vasta natureza. (Aluno E).

Nessas formulações a concepção do que seria meio ambiente ainda está centrada no senso comum. Esse pensamento mostrou-se bem sedimentado nos estudantes que apresentaram registros como os citados, visto que houve um trabalho com concepção abrangente de meio ambiente e o mesmo não conseguiu "transformar" essa percepção dos estudantes. Tal pensamento dificulta a percepção da complexidade do meio, principalmente das relações que envolvem o ser humano no e com o meio.

Após as análises expostas anteriormente, organizaram-se os estudantes em grupos de percepções que fossem similares entre si e, dessa forma, chegou-se à composição de três grupos: um em que se observaram alterações na percepção do ambiente das ruas e da escola; outro em que se observaram alterações somente na percepção do ambiente das ruas; e um em que não se observaram alterações. A partir daí, selecionaram-se estudantes desses três grupos para entrevistas de verticalização, buscando-se aprofundar o estudo e obter mais dados que fundamentassem as conclusões. Foi selecionado um aluno e uma aluna de cada grupo, com exceção do último grupo, que foi composto apenas pelo sexo feminino, o que resultou num total de cinco estudantes. As entrevistas tiveram como propósito verificar, mais uma vez, se houve a sensibilização ambiental dos alunos e que fatores podem ter influenciado ou não essa sensibilização. Como é previsto em entrevistas semiestruturadas, as perguntas podem variar a depender dos desdobramentos da entrevista.

No que diz respeito aos trabalhos realizados na escola, houve a confirmação de muitos dados obtidos no questionário exploratório, com destaque para a vinculação da escola aos espaços de socialização e interação dos adolescentes, 
além de remeter à função da escola como espaço de formação, conforme se pode constatar nestes excertos:

É que aqui todo mundo conversa com todo mundo... se socializa, né... então eles deixam um pouco esses negócios de diferença de classe de fora. Ainda que exista um pouco de grupinhos... mas assim isso está acabando. (Aluna do grupo 1).

Eu, por exemplo, me sinto confortável na escola... me sinto bem... lá tem meus amigos e tal... (Aluno do grupo 2).

É porque a escola lá... tipo assim... eu que sou aluno vou me formar ali... é ali que eu tô me tornando cidadão e muitas outras pessoas ganham a vida trabalhando lá. (Aluno do grupo 2).

Nessas opiniões se confirma a tendência, apurada em outros momentos da pesquisa, de a socialização ser posta como ponto fundamental na construção da percepção ambiental dos alunos. Nesse caso, pode-se confirmar que a escola é percebida como ambiente agradável em virtude das relações sociais mantidas nesse espaço. Outro ponto diz respeito à percepção do papel da escola na formação do cidadão. Essa percepção apareceu no segundo trabalho de campo e se manteve, pois foi confirmada por meio das entrevistas.

Um relevante aspecto para o estudo, que também apareceu nas entrevistas, foi a percepção da estrutura de funcionamento da escola. Esse tema esteve presente nas aulas de instrumentalização, o que significa que foi apropriado pela percepção dos estudantes:

Tem as cantineiras que fazem o alimento pra distribuir na cantina... tem a bibliotecária que nos ajuda [a] procurar o que nós precisamos... os professores ajudam a ensinar... a diretora coordena a escola... os próprios alunos fazem com que isso prossiga... tem a $S$., que coordena o turno. (Aluno do grupo 1).

Olha, hoje eu tô podendo notar que a violência aqui na escola melhorou muito... as pessoas não estão tão agressivas assim... a maioria tá com um objetivo fixo, que é estudar... conseguir condições para entrar em um bom emprego... conseguindo dinheiro assim, né... Então eu notei isso que a diretora tá tentando melhorar a escola, tentando fazer mais projetos... deixar os alunos estudando mais tempo... tanto que tem esses projetos ai pras crianças que elas ficam aqui o dia inteiro... tirando as crianças da rua, com certeza isto ajuda a tirá-las da violência e das drogas, então, este é um bom resultado aqui para a escola. (Aluna do grupo 1). 
Nessas transcrições os estudantes revelaram que perceberam a estrutura administrativa da escola e a divisão de trabalho inerente à instituição. Esse fato é um indicativo de que conseguiram se apropriar, de forma satisfatória, da reflexão sobre essa questão nas aulas de instrumentalização. Deve-se lembrar, também, que esses aspectos não são materiais, de modo que, quando se compara esse momento ao primeiro trabalho de campo, percebe-se considerável ganho: a ampliação da percepção dos estudantes.

Em relação aos trabalhos de campo ocorridos nas ruas do bairro, também foram obtidos dados relevantes que, em sua maioria, confirmaram a tendência à mudança, já mencionada. Uma das características ambientais mais percebidas foi o fenômeno da urbanização desordenada, verificada nestas falas:

Pra mim foi... no caso quando o rio enche, tem enchente... como o rio é muito próximo das casas [...]. (Aluno do grupo 1).

Tem porque elas sabem que ali é área de risco, elas podiam não construir lá, só que, no caso, elas não têm outro local para morar. (Aluno do grupo 1).

Tem porque elas não têm condições de morar em um lugar melhor que aquele... então é onde elas conseguem abrigo... entre aspas, viver um pouco, né? Está em um estado ruim, mas é o lugar que elas podem pagar. Por isso a gente pode ver que todas as pessoas mais bumildes moram em lugares assim. (Aluna do grupo 1).

Nas declarações a seguir nota-se que os estudantes perceberam a situação de urbanização desordenada e alguns de seus efeitos, principalmente os sociais, mencionando-os tanto nos diários de campo quanto nas entrevistas. Como a urbanização desordenada é um fenômeno marcante na paisagem do lugar e não era identificada inicialmente pela maioria dos estudantes, ressaltam-se as mudanças nas suas percepções.

Relações entre saúde e as condições do ambiente também foram referidas pelos alunos. Nesse caso, eles conseguiram estabelecer relações, mesmo que de forma inicial, entre os elementos constitutivos do ambiente e suas consequências para a qualidade de vida dos residentes no local. Essas relações são demonstradas a seguir:

Influi, porque no caso ali não tem sistema de esgoto, aí elas jogam esgoto no rio e isso atrai bicho que pode prejudicar sua saúde, no caso também as enchentes podem provocar doenças... por causa dos bichos também... e... é... prejudica a saúde também porque pode morrer por causa disso... 
pode ser que uma enchente mais forte mate as pessoas. (Aluno do grupo 1).

Algumas questões das entrevistas foram destinadas a identificar como os alunos conceituavam meio ambiente. Isso foi feito para investigar se houve mudanças significativas nas definições que eles apresentaram inicialmente sobre esse conceito.

O que eu posso entender de meio ambiente?... Olha, é muito importante na nossa vida... com certeza... Porque, se aquele córrego lá tivesse... vamos supor, não tão poluido, com certeza a saúde daquelas pessoas lá não seria tão ruim assim... Como o homem tá atacando a natureza, ela tá se voltando contra nós... tanto que a saúde daquelas pessoas ali tá um desastre porque a rua causando enchentes, acabando com um bocado de casas ali... (Aluna do grupo 1).

Sei lá, natureza, só que... o meio ambiente hoje tá meio que regaçado, né? Igual na TF... igual o córrego, por exemplo... acabaram com o córrego todo... Igual peixe... essas coisas lá você não vai achar. (Aluno do grupo 2).

Nessas formulações entende-se que os estudantes percebem meio ambiente como um conceito ligado à natureza in natura. A concepção de meio ambiente utilizada no trabalho vai muito além da exposta nos registros. O naturalismo em relação ao meio ambiente ainda permaneceu nos registros, o que demonstra como essa concepção é enraizada na cultura. Pode-se inferir que as mídias de massa têm uma parcela de responsabilidade na construção dessa noção de natureza, pois são o principal veículo de disseminação de informações em nossa sociedade. Os principais veículos de informação utilizados pelos alunos, identificados por meio do primeiro instrumento de coleta de dados, foram a televisão $(34 \%)$ e a internet $(28 \%)$, que têm a concepção em questão como central.

Uma questão relevante para a pesquisa foi identificar a influência da instrumentalização na construção da percepção ambiental dos estudantes. Nas entrevistas explorou-se como as aulas compuseram a percepção ambiental dos alunos entrevistados. Alguns textos elucidativos são apresentados a seguir:

Porque a gente sempre vê a escola como aquela coisa chata... mas aí
nesta explicação que a biblioteca servia para ensinar a gente, pra
ajudar, a sala de aula servia para outra coisa, a cantina servia para
outra... ai a gente foi criando e acreditando nesse conceito que você
passou pra gente... porque a gente tinha outros conceitos da biblioteca,
porque a biblioteca era o lugar onde você pra ficar em silêncio pra se
pesquisar... Se você não ficasse em silêncio, você tinha que ir pra fora 
da biblioteca... E que a sala de aula era um lugar [em] que você aprendia e depois ia embora... então, sei lá, ajudou a gente a ter uma visão diferente... a visão de aluno... não a visão clara daquele ambiente. (Aluna do grupo 2).

Igual quando a gente foi naquela rua, eu passei a enxergar as coisas com outros olhos... Eu via as coisas e não ligava... não é problema men e tal... e depois disso en passei a preocupar... Via as coisas e ficava imaginando o que ia acontecer e tal... sei lá.. (Aluno do grupo 2).

Tinha muita coisa que eu tinha visto, mas não tinha entendido, interpretado bem. (Aluno do grupo 2).

Essas respostas deixam claro que as aulas de instrumentalização foram elementos-chave na expansão da percepção ambiental dos estudantes, expressada nos resultados bem diferenciados no segundo momento da pesquisa. As aulas teóricas contribuíram para a reinterpretação dos ambientes por parte dos estudantes e é exatamente isso o que eles expressaram ao serem questionados sobre a importância das aulas na interpretação do ambiente. Portanto, ficou evidente que as aulas de instrumentalização tiveram importante contribuição para a construção da percepção ambiental nesta pesquisa. As percepções nos momentos pós-instrumentalização estiveram sempre, de alguma forma e em níveis diferentes, ligadas a aspectos trabalhados naquelas aulas, expressando articulações entre os dados, resultantes do contato com a realidade empírica e das elaborações teóricas sobre a mesma.

\section{Considerações finais}

Durante esta pesquisa verificou-se o potencial do trabalho de campo como estratégia para a EA na escola. No decorrer das atividades foram identificados resultados promissores e algumas limitações desta proposta, que foram discutidos à luz do referencial do trabalho.

O primeiro aspecto que deve ser ressaltado é a importância de se levarem em conta os significados que os estudantes já possuem acerca dos espaços. Isso é fundamental, visto que, no início do trabalho, o estudante já apresenta percepção sistematizada ou não sobre os espaços a serem estudados. Portanto, é fundamental que o trabalho tenha seu ponto de partida e desenho metodológico associado a essas percepções iniciais que os alunos já construíram. Uma consequência do fato de terem sido consideradas as percepções iniciais dos estudantes é o acentuado engajamento dos mesmos nas atividades. Respeitar os saberes preexistentes e permitir que eles influenciassem as etapas do trabalho foi fundamental para o sucesso das atividades realizadas. Essa participação 
possibilitou direcionar o trabalho de acordo com a percepção ambiental que os estudantes apresentavam antes das atividades e eles puderam, de fato, se sentir sujeitos na e da pesquisa.

Nos trabalhos de campo, a percepção do ambiente se configurou como principal ferramenta de trabalho, por isso é imprescindível construir roteiros que explorem a percepção sensorial dos estudantes. Esse procedimento foi uma estratégia que se mostrou eficaz quando associada a um aporte teórico. Para que isso fosse mais efetivo, foi importante não priorizar um sentido, mas pensar em formas de explorar o conjunto de todos eles.

Nesta pesquisa ficou nítido que a percepção associada ao aporte teórico é bem distinta da percepção sem esse aporte. No primeiro momento, as percepções ou eram muito fragmentadas, ou se expressavam numa construção gestaltista que assimilava "a boa forma" sem articulações que pudessem ir além do imediato percebido. Perceber a complexidade do ambiente pressupõe identificar articulações, interações, conflitos, contradições na estruturação desse ambiente, construindo condições para se posicionar diante dessa construção. Nesse contexto, a importância da articulação entre a sensibilização promovida pelo contato orientado com a realidade empírica e a instrumentalização teórica na constituição da percepção ambiental ficou muito clara. Essas atividades foram cruciais, pois introduziram elementos sem os quais os estudantes não conseguiriam ampliar suas percepções sobre aspectos do meio ambiente. Após o momento de instrumentalização, apareceram muitas relações entre os elementos do ambiente. Muitas dessas relações foram resultantes da abordagem trabalhada em sala de aula. No momento subsequente à sensibilização associada à instrumentalização, foi possível deduzir que a produção dos estudantes ganhou dimensão ampliada, mais esclarecida, apresentando nexos antes não identificados.

Perceberam-se vários elementos relevantes na prática de trabalhos de campo com a finalidade de promover a sensibilização ambiental. De acordo com a análise dos dados, pode-se considerar que a metodologia aplicada neste estudo alcançou relativo sucesso. Assim, pode-se entender que é possível e recomendável utilizar o trabalho de campo como elemento estimulador da sensibilização ambiental, mas se enfatiza que um trabalho como este ganha mais significado se for articulado a um projeto da escola, sendo, preferencialmente, planejado na perspectiva interdisciplinar, construindo uma EA escolar como prática processual no cotidiano escolar.

\section{Referências}

BRANDÃO, Carlos R. O que é educação. 26. ed. São Paulo: Brasiliense, 1991. 
BRASIL. Lei no 9.795, de 27 de abril de 1999. Dispõe sobre a educação ambiental, institui a Política Nacional de Educação Ambiental e dá outras providências. Diário Oficial da República Federativa do Brasil, Brasília, DF, 28 abr. 1999.

CHAUÍ, Marilena. Convite à Filosofia. São Paulo: Ática, 2000.

LEITE, Adriana Filgueira. O lugar: duas acepções geográficas. Anuário do Instituto de Geociências, Rio de Janeiro, v. 21, p. 9-20, 1998.

LIMA, Vanuzia Brito; ASSIS, Lenilton Francisco. Mapeando alguns roteiros de trabalho de campo em Sobral-CE: uma contribuição ao ensino de Geografia. Revista da Casa de Geografia de Sobral, Sobral, v. 6/7, n. 1, p. 109-121, 2005.

LOUREIRO, Carlos Frederico Bernardo; AMORIM, Érica Pereira; AZEVEDO, Luísa; BLANCO COSSÍO, Mauricio. Conteúdos, gestão e percepção da educação ambiental nas escolas. In: TRAJBER, Raquel; MENDONÇA, Patrícia Ramos (Org.). O que fazem as escolas que direm que farem educação ambiental? Brasília: Secretaria de Educação Continuada; UNESCO, 2006. p. 33-77.

NICOLESCU, Basarab. Um novo tipo de conhecimento: transdisciplinaridade. In: ENCONTRO CATALISADOR DO CETRANS, 1., 1999, Itatiba, SP. Anais... São Paulo: USP, 1999. p. 1-9.

REIGOTA, Marcos. Meio ambiente e representação social. 7. ed. São Paulo: Cortez. 2007.

SANTOS, Milton. 1992: a redescoberta da natureza. In: SANTOS, Milton; SILVA, Maria Auxiliadora. A redescoberta da natureza. Salvador: CRA, 2007. p. 33-43.

SOARES, Antônio Jorge. Uma concepção de meio ambiente. Direito e Liberdade, São Paulo, v. 8, n. 1, p. 27-36, 2008.

SUETERGARAY, Dirce Maria. Geografia Física (?) Geografia ambiental (?) ou Geografia e Ambiente (?). In: MEDONÇA, Francisco; KOZEL, Salete (Org.). Elementos de Epistemologia da Geografia Contemporânea. Curitiba: UFPR, 2002. p. 111-119.

Artigo recebido em 03/05/2011

Artigo aprovado em 16/09/2011 